\title{
Dr Jacques Benveniste replies:
}

Amazingly, J. Maddox, with all his experience, fell with us into the trap set by a squad of "self-appointed keepers of the scientific conscience", "with no substantial scientific published record" (J. Maddox, Nature 333, 795; 1988). Their amateurism, the climate they created in the five days of our ordeal, their inability to get to grips with our biological system and their judgement based on one dilution series dismiss this inquiry altogether. Who, with even the slightest research background, would blot out five years of our work and that of five other laboratories on such grounds?

For two years, I asked Nature to check our data. But the magician and the invigilator defined above worried me deeply. Mr Maddox assured me that he would prevent any wrongdoing. In fact, a tornado of intense and constant suspicion, fear and psychological and intellectual pressure unfit for scientific work swept our lab. Furthermore, these lesson-givers were astonishingly incompetent. In spite of my demands, no programme was set beforehand.

There were performed in 5 days $3 \times 30$ ten-fold dilutions, preparation and degranulation (35 tubes each) of 7 leukocyte samples, and eye scan of 300 chambers (about 20,000 basophils). Half of that is way beyond the weekly individual limit. The first two days of the week were spent on four open experiments. The first blood did not react even to high anti-IgE, but the three other results were superb. The fourth (counted blind upon our insistence) was "incredible": 70-75 per cent degranulation at dilutions $10,16 / 18,22$, similar to Fig. $1 b$ of the article, controls varying by the usual 15.

Then Stewart, with his typical know-itall attitude, called these results, blind though they were, valueless; that implies fraud before counting. The third day, a new dilution series was single-coded in front of a video camera, involving two major professional errors since all the visitors knew the code, when "to believe the unbelievable"? (The witness camera could not record time, nullifying that part of the procedure.) The code, wrapped into aluminium foil and in an envelope, was taped to the ceiling!

The next day, the hysteria was such that Maddox and I had to ask Stewart not to scream. He had decided also to blind the counting (an overkill) and to fill the chambers, using a modified untested method (two other serious errors). Referees must respect experimental design and not take part in it. This one was untrained and knew both codes (dilution and counts).

Here is another hard-to-believe incident: Stewart imposed a deadly silence in the counting room, yet loud laughter was heard where he was filling chambers. There, during this critical process, was Randi playing tricks, distracting the technician in charge of its supervision!

It will now be clear what a mockery of scientific inquiry this was. Only the constant implication that we had something to hide (the squad left with 1,500 photocopies!) prevented me from stopping this masquerade. On one blood, basophils could barely be counted. On the two others, controls ranged from 40 to 81 for one operator, from 35 to 61 for the other, the worst ever.

Duplicates such as 39-63 were found; if 39 were right, degranulation would have been 61 per cent at dilution 22 . Thus, the first three open and blind tests worked, controls being impeccable, whereas on the last days the test worked poorly mainly due to erratic controls. Something happened, probably the work load and modifications enforced by the "expert".

All in all,the judgement is based on one dilution tested on two bloods in awful technical and psychological conditions. Outrageous! Then, the team flew away in minutes, not leaving behind any report, nor even the data that I had to collect at Stewart's hotel that night! The report is filled with inaccuracies and distortions. Just a few: does the fact that homoeopathic companies are paying two researchers (contract approved by INSERM administration) mean that they order them into improper conduct? How about research in - or supported by - industry, including numerous Nobel prizes? We could not self-finance a long-term international cooperation nor the expenses of this large group of investigators. Did the source of the money influence their judgement? What a level of argument!

The Scotch tape was placed above all wells (see controls below). Repeating a wrong count? This detects counting errors, especially when stressed by pointed microphones and camera. The two closest counts are chosen at risk of being all wrong, as one recalibrates an illtuned machine, even in a blind experiment. The central argument bears on sampling errors and statistics of which we are so aware that we performed numerous control experiments. They show similar standard deviations and variances in 24/28 comparisons of blind ( 4 series, 90 samples, without the Israeli experiments) versus open ( 7 series, 183 samples) control wells. Did the "experts" understand that the real controls are water or anti-IgG most often paired with anti-IgE (Fig. $1 b$ )? They analysed a few curves out of 1,500 pages, but most positive data are anyhow way off 1 or 2 standard deviations. Other allergy tests correlate with degranulation (reference in article), so why is it that our statistics fit for 40 to 70 per cent degranulation at regular ligand concentration and not for the same at high dilution?

Similar double-blind experiments $(\mathrm{Br}$. J. clin. Pharm.) were under the control of an INSERM statistician, using a better non-parametric test seemingly unknown to our visitors. Then, the report auto destroys the statistical bias, declaring it "not applicable to all " (how many?) "data, for example in the 4th experiment" similar to Fig. $1 b$ or to the double-blind tests supervised by our Dean and a bailiff or Israeli scientists (tables).

Being statistically sound (which is "bloody obvious" using common sense), are all these results "made up" as snapped at me by Stewart, the very referee who cleared the paper with raw data and statistics in hand? Why then accept a paper on 13 June to publish June 30 th to destroy on 8 July data so easily spotted as wrong or made up? Is it a display to the world of the almighty anti-fraud and heterodoxy squad? Lip service is paid to our honesty; yet accusation of cheating was rampant, as shown by dismissal of the 4th experiment, Randi's mere presence and his lengthy examination of the supposedly violated code. This impinges on our honesty and scientific ability but also, without examination, on the other participating laboratories, which is unacceptable. I welcome academic exchanges on errors, if any, but will no more stand suspecting us or our associates.

More, I now believe this kind of inquiry must immediately be stopped throughout the world. Salem witchhunts or McCarthy-like prosecutions will kill science. Science flourishes only in freedom. We must not let, at any price, fear, blackmail, anonymous accusation, libel and deceit nest in our labs. Our colleagues are overwhelmingly utmost decent people, not criminals. To them, I say: never, but never, let anything like this happen - never let these people get in your lab. The only way definitively to establish conflicting results is to reproduce them. It may be that all of us are wrong in good faith. This is no crime but science as usual and only the future knows.

J. Benveniste is at INSERM U200, Université Paris-Sud, 32 rue des Carnet, 92140, Clamart, France. 